\title{
Cholecystectomy, gallstones, tonsillectomy, and pancreatic cancer risk: a population-based case-control study in minnesota
}

\author{
$\mathrm{J} \mathrm{Zhang}^{\star, 1,2}$, A E Prizment ${ }^{3}$, I B Dhakal ${ }^{4}$ and K E Anderson ${ }^{3,5}$ \\ ${ }^{1}$ Department of Epidemiology, Indiana University, Richard M. Fairbanks School of Public Health at IUPUI, Indianapolis, IN 46202, \\ USA; ${ }^{2}$ Melvin and Bren Simon Cancer Center, Indiana University, Indianapolis, IN 46202, USA; ${ }^{3}$ Division of Epidemiology and \\ Community Health, School of Public Health, University of Minnesota, Minneapolis, MN 55455, USA; ${ }^{4}$ Department of Biostatistics, \\ Fay W. Boozman College of Public Health, University of Arkansas for Medical Sciences, Little Rock, AR 72205, USA and ${ }^{5}$ Masonic \\ Cancer Center, University of Minnesota, Minneapolis, MN 55455, USA
}

Background: Associations between medical conditions and pancreatic cancer risk are controversial and are thus evaluated in a study conducted during 1994-1998 in Minnesota.

Methods: Cases $(n=215)$ were ascertained from hospitals in the metropolitan area of the Twin Cities and the Mayo Clinic. Controls $(n=676)$ were randomly selected from the general population and frequency matched to cases by age and sex. The history of medical conditions was gathered with a questionnaire during in-person interviews. Odds ratios (OR) and $95 \%$ confidence intervals $(95 \% \mathrm{Cl})$ were estimated using unconditional logistic regression.

Results: After adjustment for confounders, subjects who had cholecystectomy or gallstones experienced a significantly higher risk of pancreatic cancer than those who did not (OR (95\% Cl): 2.11 (1.32-3.35) for cholecystectomy and 1.97 (1.23-3.12) for gallstones), whereas opposite results were observed for tonsillectomy $(0.67(0.48-0.94))$. Increased risk associated with cholecystectomy was the greatest when it occurred $\leqslant 2$ years before the cancer diagnosis $(5.93$ (2.36-15.7)) but remained statistically significant when that interval was $\geqslant 20$ years $(2.27(1.16-4.32))$.

Conclusions: Cholecystectomy, gallstones, and tonsillectomy were associated with an altered risk of pancreatic cancer. Our study suggests that cholecystectomy increased risk but reverse causality may partially account for high risk associated with recent cholecystectomy.

Pancreatic cancer is the fourth leading cause of cancer death in the US (American Cancer Society, 2013). The International Agency for Research on Cancer has estimated that 138100 men and 127900 women died from this malignancy worldwide in 2008 (Jemal et al, 2011). Despite high mortality, pancreatic cancer etiology virtually remains obscure (Olson and Kurtz, 2013). Although cigarette smoking has been established as a risk factor, it accounts for only about $25-30 \%$ of the variation of the disease (Silverman et al, 1999; Hassan et al, 2007). It is apparent that more risk factors need to be identified to enable the primary prevention of pancreatic cancer.
Cholecystectomy, gallstones (cholelithiasis), and tonsillectomy are common medical conditions/procedures (Lin and Kessler, 1981; Gullo et al, 1996). To date, at least 13 epidemiologic studies have investigated the associations of cholecystectomy and/or gallstones with pancreatic cancer risk. The results obtained from these studies are overall conflicting (Lin and Kessler, 1981; Ekbom et al, 1996; Gullo et al, 1996; Chow et al, 1999; Coughlin et al, 2000; Silverman, 2001; Talamini et al, 2001; Ye et al, 2001; Lin et al, 2002; Schernhammer et al, 2002; Stolzenberg-Solomon et al, 2002; Hassan et al, 2007; Lipworth et al, 2011). Significantly increased

*Correspondence: Dr J Zhang; E-mail: JZ21@iu.edu

Received 8 November 2013; revised 27 February 2014; accepted 28 February 2014; published online 25 March 2014

(c) 2014 Cancer Research UK. All rights reserved 0007-0920/14 
risk associated with cholecystectomy and/or gallstones was observed in one case-control study (Silverman, 2001) and four cohort studies (Ekbom et al, 1996; Chow et al, 1999; Coughlin et al, 2000; Lin et al, 2002). However, null associations were found among four case-control studies (Lin and Kessler, 1981; Gullo et al, 1996; Hassan et al, 2007; Lipworth et al, 2011) and four cohort studies (Talamini et al, 2001; Ye et al, 2001; Schernhammer et al, 2002; Stolzenberg-Solomon et al, 2002). Cholecystectomy and/or gallstones may occur as a manifestation of subclinical pancreatic cancer (Hassan et al, 2007; Lipworth et al, 2011). Therefore, one of the potential reasons for these discrepant findings is that many previous studies failed to consider the time interval between diagnosis of medical conditions and of pancreatic cancer (Lin and Kessler, 1981; Ekbom et al, 1996; Chow et al, 1999; Coughlin et al, 2000; Lin et al, 2002; Stolzenberg-Solomon et al, 2002).

Tonsils are organs of lymphoid tissue that constitute the first line of defense of the immune system against invading pathogens. Tonsillectomy is usually performed following repeated occurrence of acute tonsillitis and airway obstruction (Vestergaard et al, 2010). Data are scarce on whether tonsillectomy has any influence on pancreatic cancer risk (Lin and Kessler, 1981). The present study thereby sought to evaluate cholecystectomy, gallstones, and tonsillectomy in relation to the risk of this fatal disease in a population-based case-control study in Minnesota.

\section{MATERIALS AND METHODS}

Study population. The present study was performed within a case-control study conducted from April 1994 to September 1998 in Minnesota, and the design and methods of this epidemiologic study have been described in detail elsewhere (Gross et al, 1999; Anderson et al, 2002). Briefly, the source cohort was The Upper Midwest of the US. Cases were subjects with newly diagnosed cancer of the exocrine pancreas (International Classification of Disease for Oncology, third edition, code C25), confirmed by histology, cytology, or clinical symptoms consistent with pancreas cancer. All pathology reports of potential cases were reviewed by a pathologist or confirmed through the Minnesota Cancer Surveillance System for eligibility. Cases were ascertained from all hospitals in the seven-county metropolitan area of the Twin Cities (Minneapolis and St Paul), Minnesota, and the Mayo Clinic (only cases residing in The Upper Midwest were recruited from the Mayo Clinic). A rapid case-ascertainment system was employed to recruit cases because pancreatic cancer is rapidly fatal. As a result, the median number of days between diagnosis and first contact for the study was only 13 days for the cases enroled in the study. Pancreatic cancer cases were eligible if they were 20 years of age or older, spoke English, and were mentally competent. Of 460 eligible cases identified, 202 did not participate in the study due to death before contact or interview $(n=85)$, refusal of cases $(n=79)$, refusal of physicians $(n=31)$, and inability to contact cases $(n=7)$. Therefore, 258 cases completed the study; thus the response rate was $56.1 \%$.

Controls were randomly selected from the seven-county metropolitan area of the Twin Cities. While controls aged 20-64 years were identified from the drivers' license and state identity card database, those aged 65 years or older were ascertained from US Health Care Financing Administration (now Centers for Medicare \& Medicaid Services) records. Controls were frequency matched to cases by age (within 5 years) and sex. Race was not used as a matching variable because the vast majority of study subjects (97.2\%) were of European descent. Inclusion criteria for controls were the same as those for cases, disallowing diagnosis of pancreatic cancer. Of 1141 eligible controls identified, 676 participated in the study, which yields a response rate of $59.2 \%$.
After excluding 43 cases without data on all three medical conditions considered, 215 cases (including 72 cases recruited from the Mayo Clinic) and 676 controls are available for the analysis of the present study.

Data collection. The study protocol was approved by the Institutional Review Boards of the University of Minnesota and the Mayo Clinic. Before interview, written, informed consent was obtained from all cases and controls. All participants were interviewed in person with a basic questionnaire and a food frequency questionnaire (FFQ). The basic questionnaire elicited information on demographics, socioeconomics, physical activity, cigarette smoking, and medical history. Both occupational and leisure-time activities were evaluated. The participants were asked to report the number of hours per week they usually spent on light, moderate, and heavy activities in the year before pancreatic cancer diagnosis for cases or the past year for controls. The total amount of physical activity (h per week) was calculated by summing the three levels of the activities. Data on the status (never, former, and current), amount (cigarettes per day), and duration (years) of cigarette smoking were collected from participants.

Information on cholecystectomy, gallstones, tonsillectomy, and diabetes was collected. If a subject reported a history of one or more of these medical conditions, the year of diagnosis of the condition(s) (except gallstones) was also recorded. A slightly modified version of the Willett FFQ was used to assess diet during the year before pancreatic cancer diagnosis for cases or the past year for controls (Willett et al, 1987). This dietary assessment instrument covered 153 items of food or food groups frequently consumed by the general population in the US and also contained questions on alcohol intake (serving per week). Dietary intakes of energy and nutrients were calculated by multiplying the amount in a pre-specified portion size of each food item by the reported average frequency of consumption and summing over all food items. The amounts of energy and nutrients for the portion size of each of the food items surveyed were estimated on the basis of a nutrient database developed for the Minnesota Colon Cancer Prevention Research Unit studies.

Statistical analysis. Pancreatic cancer risk, in relation to each of the three medical conditions considered, was estimated as odds ratios (OR) and 95\% confidence intervals (95\% CI) by unconditional logistic regression. Subjects without a given condition were treated as the reference group to evaluate risk for those with that condition. Crude and multivariable-adjusted ORs were calculated for each of the three conditions examined. The confounders initially adjusted in the regression models include age, sex, race (white, black, and other), education (three levels), cigarette smoking (never, former, and current), alcohol drinking (serving per week), physical activity (h per week), energy intake, and diabetes (yes, no). Education, alcohol drinking, and energy intake were dropped from the final models because they did not substantively alter ORs (i.e., <10\%). Evaluating whether energy intake and alcohol drinking were real confounders was confined to 167 cases and 554 controls whose diet was assessed with the FFQ described above.

The diagnosis of gallstones or need for cholecystectomy may be simply driven by clinical manifestation of an insidious pancreatic cancer (Schernhammer et al, 2002). The availability of data on the year of cholecystectomy allows us to evaluate whether reverse causality exists between this condition and pancreatic cancer risk. Specifically, risk was estimated by the time interval between the year of cholecystectomy and the year of cancer diagnosis (i.e., no cholecystectomy $v s \leqslant 2$ years, 3-19 years, and $\geqslant 20$ years). A $P$-value of $<0.05$ (two-sided) was considered statistically significant. All statistical analyses were conducted with the SAS (version 9.3; SAS Institute Inc., Cary, NC, USA). 


\section{RESULTS}

Characteristics of cases and controls are shown in Table 1. Mean age was 66.0 years for both cases and controls. No statistically significant differences in age and sex existed between cases and controls, suggesting the success of frequency-matching controls to cases by these two variables. Cases were less physically active but more likely to be a smoker or have diabetes than controls (all $P<0.05)$. Cholecystectomy and gallstones were more common in cases than in controls (both $P<0.001$ ), whereas the proportion of tonsillectomy was not statistically different between cases and controls. Of 118 subjects diagnosed with gallstones, 91 (77\%) received cholecystectomy.

After adjustment for age, sex, race, smoking status, physical activity, and diabetes, both cholecystectomy and gallstones were associated with a significantly increased risk of pancreatic cancer (OR (95\% CI): $2.11(1.32-3.35)$ for cholecystectomy and 1.97 (1.23-3.12) for gallstones) (Table 2). Compared with subjects without a history of cholecystectomy, the adjusted OR (95\% CI) was $5.93(2.36-15.7), 1.31(0.57-2.75)$, and $2.27(1.16-4.32)$ for

Table 1. Characteristics of cases and controls in a population-based casecontrol study of pancreatic cancer in Minnesota, 1994-1998

\begin{tabular}{|c|c|c|c|}
\hline Characteristics & $\begin{array}{c}\text { Cases } \\
(n=215)^{b}\end{array}$ & $\begin{array}{l}\text { Controls } \\
(n=676)\end{array}$ & $P$-value \\
\hline Age (years) ${ }^{c}$ & $66.0(11.4)$ & $66.0(12.5)$ & 0.99 \\
\hline \multicolumn{4}{|l|}{ Sex } \\
\hline Male & 125 (58.4\%) & 381 (56.4\%) & \multirow[t]{2}{*}{0.60} \\
\hline Female & 89 (41.6\%) & 295 (43.6\%) & \\
\hline \multicolumn{4}{|l|}{ Race } \\
\hline White & 201 (93.9\%) & $664(98.2 \%)$ & \multirow[t]{3}{*}{0.002} \\
\hline Black & $9(4.2 \%)$ & $5(0.7 \%)$ & \\
\hline Other & $4(1.9 \%)$ & $7(1.1 \%)$ & \\
\hline \multicolumn{4}{|l|}{ Cigarette smoking } \\
\hline Never smoker & $80(38.1 \%)$ & $317(46.9 \%)$ & \multirow[t]{3}{*}{0.046} \\
\hline Former smoker & $96(45.7 \%)$ & 281 (41.6\%) & \\
\hline Current smoker & $34(16.2 \%)$ & 78 (11.5\%) & \\
\hline Physical activity (h per week) ${ }^{c}$ & $36.7(22.9)$ & $44.3(22.0)$ & $<0.0001$ \\
\hline \multicolumn{4}{|l|}{ Diabetes } \\
\hline Yes & $51(25.6 \%)$ & $52(7.7 \%)$ & \multirow[t]{2}{*}{$<0.0001$} \\
\hline No & 148 (74.4\%) & $624(92.3 \%)$ & \\
\hline \multicolumn{4}{|l|}{ Cholecystectomy } \\
\hline Yes & 48 (23.7\%) & $72(10.7 \%)$ & \multirow[t]{2}{*}{$<0.0001$} \\
\hline No & $155(76.4 \%)$ & $604(89.4 \%)$ & \\
\hline \multicolumn{4}{|l|}{ Gallstones } \\
\hline Yes & $42(21.8 \%)$ & $78(11.6 \%)$ & \multirow[t]{2}{*}{0.0003} \\
\hline No & $151(78.2 \%)$ & $597(88.4 \%)$ & \\
\hline \multicolumn{4}{|l|}{ Tonsillectomy } \\
\hline Yes & $100(48.3 \%)$ & $374(55.4 \%)$ & \multirow[t]{2}{*}{0.073} \\
\hline No & 107 (51.7\%) & 301 (44.6\%) & \\
\hline \multicolumn{4}{|c|}{$\begin{array}{l}\text { a Data were missing for cases (n) on sex (1), race (1), cigarette smoking (5), physical activity } \\
\text { (23), diabetes (16), cholecystectomy (12), gallstones (22), and tonsillectomy (8), and controls } \\
\text { (n) on physical activity (3), gallstones (1), and tonsillectomy (1). } \\
b_{72} \text { cases were recruited from the Mayo Clinic. } \\
{ }^{c} \text { Values given are means (s.d.). }\end{array}$} \\
\hline
\end{tabular}

those whose cholecystectomy was conducted $\leqslant 2$ years, 3-19 years, and $\geqslant 20$ years before diagnosis of pancreatic cancer, respectively (Table 3). Subjects who received a tonsillectomy experienced a $33 \%$ lower risk than those who did not (OR (95\% CI): 0.67 (0.48-0.94)) (Table 2).

After excluding 17 subjects undergoing cholecystectomy for reasons other than gallstones, an increased risk of pancreatic cancer associated with this surgery materially remained unchanged (OR (95\% CI): 1.92 (1.16-3.14)). Additional adjustment for the participating center (the Twin Cities vs the Mayo Clinic) somewhat attenuated elevated risk associated with cholecystectomy performed $\geqslant 20$ years before diagnosis of pancreatic cancer (OR (95\% CI): 1.91 (0.81-3.77)), but did not markedly changed other ORs observed for cholecystectomy, gallstones, or tonsillectomy. Controlling for cigarette smoking by using pack-years did not result in substantive changes in obtained risk estimates.

\section{DISCUSSION}

In the present study, cholecystectomy and gallstones were associated with a significantly increased risk of pancreatic cancer after adjustment for confounders, whereas tonsillectomy was associated with a significantly decreased risk. Furthermore, elevated risk was the highest for recent cholecystectomy $(\leqslant 2$ years before cancer diagnosis) but remained statistically significant for remote cholecystectomy ( $\geqslant 20$ years).

Current epidemiologic evidence for associations between selected medical conditions and pancreatic cancer risk is controversial (Olson, 2012). Of 13 studies that have evaluated cholecystectomy and/or gallstones in relation to the occurrence of this malignancy (Lin and Kessler, 1981; Ekbom et al, 1996; Gullo et al, 1996; Chow et al, 1999; Coughlin et al, 2000; Silverman, 2001; Talamini et al, 2001; Ye et al, 2001; Lin et al, 2002; Schernhammer et al, 2002; Stolzenberg-Solomon et al, 2002; Hassan et al, 2007; Lipworth et al, 2011), four studies reported an increased risk for subjects with a history of cholecystectomy (Ekbom et al, 1996; Coughlin et al, 2000; Silverman, 2001; Lin et al, 2002). A 20\% elevated risk was found in the American Cancer Society Cancer Prevention Study II (Coughlin et al, 2000). However, this positive association was not found in six other studies (Lin and Kessler, 1981; Gullo et al, 1996; Talamini et al, 2001; Ye et al, 2001; Schernhammer et al, 2002; Hassan et al, 2007). It should be pointed out that the time interval between cholecystectomy and pancreatic cancer diagnosis was not considered in most previous studies (Lin and Kessler, 1981; Ekbom et al, 1996; Gullo et al, 1996; Chow et al, 1999; Coughlin et al, 2000; Silverman, 2001; Talamini et al, 2001; Ye et al, 2001; Lin et al, 2002; Schernhammer et al, 2002; Stolzenberg-Solomon et al, 2002; Hassan et al, 2007; Lipworth et al, 2011). In a large case-control study conducted in the US, a significantly increased risk was found for subjects with cholecystectomy performed 2 years or less before diagnosis of pancreatic cancer (OR (95\% CI): 3.9 (2.4-6.4)), but this positive association disappeared when analysis was confined to subjects with this condition over 2 years before cancer diagnosis (OR (95\% CI): $1.1(0.9-1.8)$ ) (Hassan et al, 2007). The results obtained from that US study were similar to those in a Swedish study (Ye et al, 2001). In addition, a descriptive epidemiologic study did not report a significant increase in pancreatic cancer incidence in the US during 1992-1996 after the widespread adoption of laparoscopic cholecystectomy in 1991, although a long-term effect of this medical event could not be entirely ruled out (Urbach et al, 2001).

We found that the apparent effect of cholecystectomy was the strongest when it occurred 2 years or less before the cancer diagnosis, became substantially weaker when that interval was longer than 2 years, but was still statistically significant even when 
Table 2. Risk of pancreatic cancer in relation to selected medical conditions in a population-based case-control study in Minnesota, 1994-1998

\begin{tabular}{|c|c|c|c|c|}
\hline Condition & No. of cases & No. of controls & Crude OR $(95 \% \mathrm{Cl})$ & Adjusted OR $(95 \% \mathrm{Cl})^{a}$ \\
\hline \multicolumn{5}{|c|}{ Cholecystectomy } \\
\hline $\begin{array}{l}\text { No } \\
\text { Yes }\end{array}$ & $\begin{array}{r}155 \\
48\end{array}$ & $\begin{array}{r}604 \\
72\end{array}$ & $\begin{array}{c}1.00 \text { (Referent) } \\
2.60(1.73-3.89)\end{array}$ & $\begin{array}{c}1.00 \text { (Referent) } \\
2.11(1.32-3.35)\end{array}$ \\
\hline \multicolumn{5}{|l|}{ Gallstones } \\
\hline $\begin{array}{l}\text { No } \\
\text { Yes }\end{array}$ & $\begin{array}{r}151 \\
42\end{array}$ & $\begin{array}{r}597 \\
78\end{array}$ & $\begin{array}{c}1.00 \text { (Referent) } \\
2.13(1.40-3.21)\end{array}$ & $\begin{array}{c}1.00 \text { (Referent) } \\
1.97(1.23-3.12)\end{array}$ \\
\hline \multicolumn{5}{|c|}{ Tonsillectomy } \\
\hline $\begin{array}{l}\text { No } \\
\text { Yes }\end{array}$ & $\begin{array}{l}107 \\
100\end{array}$ & $\begin{array}{l}301 \\
374\end{array}$ & $\begin{array}{c}1.00 \text { (Referent) } \\
0.75 \text { (0.55-1.03) }\end{array}$ & $\begin{array}{c}1.00 \text { (Referent) } \\
0.67(0.48-0.94)\end{array}$ \\
\hline
\end{tabular}

Table 3. Risk of pancreatic cancer in relation to time since cholecystectomy in a population-based case-control study in Minnesota, 1994-1998

\begin{tabular}{|c|c|c|c|c|}
\hline Cholecystectomy & No. of cases & No. of controls & Crude OR $(95 \% \mathrm{Cl})$ & Adjusted OR $(95 \% \mathrm{Cl})^{\mathrm{a}}$ \\
\hline None & 155 & 604 & 1.00 (Referent) & 1.00 (Referent) \\
\hline$\leqslant 2$ years & 17 & 8 & $8.28(3.61-20.6)$ & $5.93(2.36-15.7)$ \\
\hline $3-19$ years & 10 & 31 & $1.26(0.57-2.53)$ & $1.31(0.57-2.75)$ \\
\hline$\geqslant 20$ years & 17 & 32 & $2.07(1.10-3.78)$ & $2.27(1.16-4.32)$ \\
\hline
\end{tabular}

that interval was 20 years or more. Our results regarding time since cholecystectomy were consistent with those of a multi-center casecontrol study (Silverman et al, 1999). Reverse causality may partially account for high risk associated with recent cholecystectomy because this surgery might be performed for the gallstones or other gallbladder diseases that appeared as clinical symptoms and signs of an early-stage pancreatic cancer. Asymptomatic gallstones may also be incidentally discovered during the diagnostic process for subjects presenting with abdominal pain and incorrectly attributed as the cause that is really a result of cancer. However, our observation of significantly elevated risk for subjects with remote cholecystectomy suggests that this gallbladder disease also influences pancreatic cancer risk aside from reverse causality or coincidence.

Discrepant results have also been reported for gallstones. Four studies revealed a positive association between gallstones and pancreatic cancer risk (Gullo et al, 1996; Chow et al, 1999; Coughlin et al, 2000; Lipworth et al, 2011). However, this association was no longer statistically significant in the two of those studies when subjects with gallstones diagnosed within 2 years of cancer diagnosis were deleted from analysis (Gullo et al, 1996; Lipworth et al, 2011). In an Italian study, a significantly increased risk was observed for recently detected gallstones (OR (95\% CI): $3.53(1.67-7.45))$ but not for gallstones detected over 2 years before cancer diagnosis (Lipworth et al, 2011). Our study found a significant, positive association between presence of gallstones and risk of pancreatic cancer. We did not consider timing for the effect of gallstones due to lack of data. However, timing-related risk estimates for gallstones are expected to be similar to those of cholecystectomy because $77 \%$ of subjects diagnosed with gallstones underwent cholecystectomy in our study population. Symptomatic gallstone disease is a common indication for cholecystectomy (Duca et al, 2003). As cholecystokinin has trophic effect on the pancreas, it has been put forward that elevated risk associated with gallstones is ascribed to the increased release of cholecystokinin following cholecystectomy (Talamini et al, 2001).

After adjustment for cigarette smoking and other risk factors, tonsillectomy was associated with a significantly reduced risk of pancreatic cancer in our study. Of the eight studies that have evaluated this association (Wynder et al, 1973; Lin and Kessler, 1981; Gold et al, 1985; Mack et al, 1986; Mills et al, 1988; Farrow and Davis, 1990; Bueno de Mesquita et al, 1992; Kalapothaki et al, 1993), six revealed a lower risk associated with tonsillectomy (Lin and Kessler, 1981; Gold et al, 1985; Mack et al, 1986; Mills et al, 1988; Farrow and Davis, 1990; Bueno de Mesquita et al, 1992), and the beneficial effect attained statistical significance in three of them (Lin and Kessler, 1981; Gold et al, 1985; Farrow and Davis, 1990). It should be mentioned that only two of those previous studies included adjustment for cigarette smoking (Gold et al, 1985; Bueno de Mesquita et al, 1990). The reduced risk for tonsillectomy, which was observed in the present study and some other studies, implies that alterations in immunity may have a role in pancreatic cancer etiology (Farrow and Davis, 1990). Toll-like receptors (TLRs) function in innate immunity by recognising structurally conserved molecules on microbes. It was found that expression of TLR2, TLR3, and TLR5 was increased in T cytotoxic (CD8) lymphocytes derived from recurrently infected tonsils (a main indicator for tonsillectomy) compared with the CD8 cells from control tonsils (Mansson et al, 2006). Some changes in humoral immunity were also observed. One study revealed that parotid salivary immunoglobulin A was elevated within the first year after tonsillectomy (Childers et al, 2001). It appears that enhanced immunity may 
offer some explanations for potential benefit of tonsillectomy, which gains further support from a pooled analysis of 10 casecontrol studies in which a significantly lower risk of pancreatic cancer was found for subjects with any allergy and some specific allergies (Olson et al, 2013).

Our study has some advantages over previous studies. The risk estimates reported in the present study were controlled for most established and potential confounders. We examined the association between cholecystectomy and pancreatic cancer in terms of time since the diagnosis of this surgical procedure. Such an approach made it possible for us to evaluate the possibility of reverse causality.

The present study also has several weaknesses. Recall bias and selection bias should be always considered in case-control studies. Recall bias occurs when cases are more or less likely to report exposure(s) of interest than controls. In contrast to the common misreporting of dietary and other lifestyle factors (Goris et al, 2000; Zhang et al, 2000), subjects generally have a relatively accurate recall of the occurrence of the medical conditions considered in our analysis, as there was no clear reason for them to misreport personal history of gallbladder disease. The response rate for both cases and controls was less than $60 \%$. This suggests that selection bias might have somewhat distorted our results because it is possible that respondents differed from non-respondents with regard to their demographic, socioeconomic, and lifestyle factors.

Detection bias might arise as cases were more likely than controls to receive abdominal diagnostic examinations (e.g. ultrasound, X-ray, and/or CT scan) and thereby to be diagnosed with asymptomatic gallstones or other gallbladder diseases. Given the absence of data on the history of these medical examinations for our study subjects, we are unable to estimate whether and to what extent the detection bias have influenced our observed results for gallstones and cholecystectomy. In the present study, cases of pancreatic cancer were enroled from Midwest residents attending the Mayo Clinic and from all hospitals in the Twin Cities metropolitan area with a rapid case-ascertainment system. Recruitment was also conducted with assistance from Minnesota Cancer Surveillance System and local tumour registries. These methods might have biased recruitment towards patients with early-stage, resectable pancreatic cancer as compared with the total population of eligible cases. However, ascertaining cases from population-based cancer registries alone was not feasible owing to the time needed for physicians to report cancer diagnosis to cancer registries and the rapid fatality of this malignancy. As 22 cases with missing data on gallstones were significantly younger and more likely to be female than 193 cases with data on this gallbladder disease (data not shown), our reported results might have been different to some extent if such data were available for those 22 cases and were included in analysis. However, those cases with missing information were not significantly different in race, smoking status, physical activity, and diabetes from the other 193 cases.

A relatively small number of cases were enroled in the present study, and therefore some of our findings may be due to chance. Body mass index was not measured due to an oversight and thus was not adjusted as a confounder in our study. Energy intake and physical activity are main determinants of overweight and obesity. Physical activity was controlled for in the logistic regression models from which risk estimates are presented in Tables 2 and 3. As stated previously, additional adjustment for energy intake did not materially change our results. Nevertheless, it is possible that our findings might have been distorted by residual confounding by body mass index.

In summary, the present study revealed that cholecystectomy and gallstones are associated with an increased risk of pancreatic cancer, whereas tonsillectomy is associated with a reduced risk. The strong association with recent cholecystectomy might be explained in part by reverse causality or detection bias. More epidemiologic studies are warranted to further investigate whether the medical conditions considered in this study are causally associated with pancreatic cancer risk. Such studies are important because identifying risk factors helps to formulate the preventive strategies for this dreadful disease.

\section{ACKNOWLEDGEMENTS}

This study was supported by the Medical Research Endowment Award, University of Arkansas for Medical Sciences (JZ) and a grant from the National Institutes of Health (CA58697, KEA). The authors thank Lori Strayer (Division of Epidemiology and Community Health, University of Minnesota, Minneapolis, Minnesota, USA) for her technical assistance during preparation of the manuscript. AEP was supported as a postdoctoral fellow by training grant T32CA132670 (PI: KEA) from the National Cancer Institute.

\section{CONFLICT OF INTEREST}

The authors declare no conflict of interest.

\section{REFERENCES}

American Cancer Society (2013) Cancer Facts \& Figures. American Cancer Society: Atlanta, GA, USA.

Anderson KE, Sinha R, Kulldorff M, Gross M, Lang NP, Barber C, Harnack L, DiMagno E, Bliss R, Kadlubar FF (2002) Meat intake and cooking techniques: associations with pancreatic cancer. Mutat Res 506-507: 225-231.

Bueno de Mesquita HB, Maisonneuve P, Moerman CJ, Walker AM (1992) Aspects of medical history and exocrine carcinoma of the pancreas: a population-based case-control study in The Netherlands. Int J Cancer $\mathbf{5 2}$ 17-23.

Bueno de Mesquita HB, Moerman CJ, Runia S, Maisonneuve P (1990) Are energy and energy-providing nutrients related to exocrine carcinoma of the pancreas? Int J Cancer 46: 435-444.

Childers NK, Powell WD, Tong G, Kirk K, Wiatrak B, Michalek SM (2001) Human salivary immunoglobulin and antigen-specific antibody activity after tonsillectomy. Oral Microbiol Immunol 16: 265-269.

Chow WH, Johansen C, Gridley G, Mellemkjaer L, Olsen JH, Fraumeni JF Jr (1999) Gallstones, cholecystectomy and risk of cancers of the liver, biliary tract and pancreas. Br J Cancer 79: 640-644.

Coughlin SS, Calle EE, Patel AV, Thun MJ (2000) Predictors of pancreatic cancer mortality among a large cohort of United States adults. Cancer Causes Control 11: 915-923.

Duca S, Bala O, Al-Hajjar N, Lancu C, Puia IC, Munteanu D, Graur F (2003) Laparoscopic cholecystectomy: incidents and complications. A retrospective analysis of 9542 consecutive laparoscopic operations. HPB (Oxford) 5: 152-158.

Ekbom A, Yuen J, Karlsson BM, McLaughlin JK, Adami HO (1996) Risk of pancreatic and periampullar cancer following cholecystectomy: a population-based cohort study. Dig Dis Sci 41: 387-391.

Farrow DC, Davis S (1990) Risk of pancreatic cancer in relation to medical history and the use of tobacco, alcohol and coffee. Int J Cancer 45: 816-820.

Gold EB, Gordis L, Diener MD, Seltser R, Boitnott JK, Bynum TE, Hutcheon DF (1985) Diet and other risk factors for cancer of the pancreas. Cancer 55: 460-467.

Goris AH, Westerterp-Plantenga MS, Westerterp KR (2000) Undereating and underrecording of habitual food intake in obese men: selective underreporting of fat intake. Am J Clin Nutr 71: 130-134.

Gross M, Kruisselbrink T, Anderson K, Lang N, McGovern P, Delongchamp R, Kadlubar F (1999) Distribution and concordance of N-acetyltransferase genotype and phenotype in an American population. Cancer Epidemiol Biomarkers Prev 8: 683-692. 
Gullo L, Pezzilli R, Morselli-Labate AM. Italian Pancreatic Cancer Study G (1996) Risk of pancreatic cancer associated with cholelithiasis, cholecystectomy, or gastrectomy. Dig Dis Sci 41: 1065-1068.

Hassan MM, Bondy ML, Wolff RA, Abbruzzese JL, Vauthey JN, Pisters PW, Evans DB, Khan R, Chou TH, Lenzi R, Jiao L, Li D (2007) Risk factors for pancreatic cancer: case-control study. Am J Gastroenterol 102: 2696-2707.

Jemal A, Bray F, Center MM, Ferlay J, Ward E, Forman D (2011) Global cancer statistics. CA Cancer J Clin 61: 69-90.

Kalapothaki V, Tzonou A, Hsieh CC, Karakatsani A, Trichopoulou A, Toupadaki N, Trichopoulos D (1993) Nutrient intake and cancer of the pancreas: a case-control study in Athens, Greece. Cancer Causes Control 4 383-389.

Lin RS, Kessler II (1981) A multifactorial model for pancreatic cancer in man. Epidemiologic evidence. JAMA 245: 147-152.

Lin Y, Tamakoshi A, Kawamura T, Inaba Y, Kikuchi S, Motohashi Y, Kurosawa M, Ohno Y (2002) Risk of pancreatic cancer in relation to alcohol drinking, coffee consumption and medical history: findings from the Japan collaborative cohort study for evaluation of cancer risk. Int $J$ Cancer 99: 742-746.

Lipworth L, Zucchetto A, Bosetti C, Franceschi S, Talamini R, Serraino D, McLaughlin JK, La Vecchia C, Negri E (2011) Diabetes mellitus, other medical conditions and pancreatic cancer: a case-control study. Diabetes Metab Res Rev 27: 255-261.

Mack TM, Yu MC, Hanisch R, Henderson BE (1986) Pancreas cancer and smoking, beverage consumption, and past medical history. J Natl Cancer Inst 76: 49-60.

Mansson A, Adner M, Cardell LO (2006) Toll-like receptors in cellular subsets of human tonsil T cells: altered expression during recurrent tonsillitis. Respir Res 7: 36.

Mills PK, Beeson WL, Abbey DE, Fraser GE, Phillips RL (1988) Dietary habits and past medical history as related to fatal pancreas cancer risk among Adventists. Cancer 61: 2578-2585.

Olson SH (2012) Selected medical conditions and risk of pancreatic cancer. Mol Carcinog 51: 75-97.

Olson SH, Hsu M, Satagopan JM, Maisonneuve P, Silverman DT, Lucenteforte E, Anderson KE, Borgida A, Bracci PM, Bueno-de-Mesquita HB, Cotterchio M, Dai Q, Duell EJ, Fontham EH, Gallinger S, Holly EA, Ji BT, Kurtz RC, La Vecchia C, Lowenfels AB, Luckett B, Ludwig E, Petersen GM, Polesel J, Seminara D, Strayer L, Talamini R. Pancreatic Cancer Case-Control Consortium (2013) Allergies and risk of pancreatic cancer: a pooled analysis from the pancreatic cancer case-control consortium. Am J Epidemiol 178: 691-700.
Olson SH, Kurtz RC (2013) Epidemiology of pancreatic cancer and the role of family history. J Surg Oncol 107: 1-7.

Schernhammer ES, Michaud DS, Leitzmann MF, Giovannucci E, Colditz GA, Fuchs CS (2002) Gallstones, cholecystectomy, and the risk for developing pancreatic cancer. Br J Cancer 86: 1081-1084.

Silverman DT (2001) Risk factors for pancreatic cancer: a case-control study based on direct interviews. Teratog Carcinog Mutagen 21: 7-25.

Silverman DT, Schiffman M, Everhart J, Goldstein A, Lillemoe KD, Swanson GM, Schwartz AG, Brown LM, Greenberg RS, Schoenberg JB, Pottern LM, Hoover RN, Fraumeni Jr JF (1999) Diabetes mellitus, other medical conditions and familial history of cancer as risk factors for pancreatic cancer. Br J Cancer 80: 1830-1837.

Stolzenberg-Solomon RZ, Pietinen P, Taylor PR, Virtamo J, Albanes D (2002) A prospective study of medical conditions, anthropometry, physical activity, and pancreatic cancer in male smokers (Finland). Cancer Causes Control 13: 417-426.

Talamini G, Falconi M, Bassi C, Casetti L, Fantin A, Salvia R, Pederzoli P (2001) Previous cholecystectomy, gastrectomy, and diabetes mellitus are not crucial risk factors for pancreatic cancer in patients with chronic pancreatitis. Pancreas 23: 364-367.

Urbach DR, Swanstrom LL, Khajanchee YS, Hansen PD (2001) Incidence of cancer of the pancreas, extrahepatic bile duct and ampulla of Vater in the United States, before and after the introduction of laparoscopic cholecystectomy. Am J Surg 181: 526-528.

Vestergaard H, Westergaard T, Wohlfahrt J, Hjalgrim H, Melbye M (2010) Tonsillitis, tonsillectomy and Hodgkin's lymphoma. Int J Cancer 127: 633-637.

Willett WC, Reynolds RD, Cottrell-Hoehner S, Sampson L, Browne ML (1987) Validation of a semi-quantitative food frequency questionnaire: comparison with a 1-year diet record. J Am Diet Assoc 87: 43-47.

Wynder EL, Mabuchi K, Maruchi N, Fortner JG (1973) A case control study of cancer of the pancreas. Cancer 31: 641-648.

Ye W, Lagergren J, Nyren O, Ekbom A (2001) Risk of pancreatic cancer after cholecystectomy: a cohort study in Sweden. Gut 49: 678-681.

Zhang J, Temme EH, Sasaki S, Kesteloot H (2000) Under- and overreporting of energy intake using urinary cations as biomarkers: relation to body mass index. Am J Epidemiol 152: 453-462.

This work is published under the standard license to publish agreement. After 12 months the work will become freely available and the license terms will switch to a Creative Commons AttributionNonCommercial-Share Alike 3.0 Unported License. 